\title{
Effects of pulmonary function in short duration exposed automobile spray painters
}

\author{
Revathi $\mathrm{M}^{1}$, Chandrasekhar $\mathrm{M}^{2}$ \\ ${ }^{I}$ Assistant Professor, Department of Physiology, Meenakshi Medical College and Research Institute, Enathur, \\ Kanchipuram-631552, Tamilnadu, India. \\ ${ }^{2}$ Professor \& HOD, Department of Physiology, Meenakshi Medical College and Research Institute, Enathur, \\ Kanchipuram-631552, Tamilnadu, India
}

\begin{abstract}
Objective: Individuals engaged in car painting are at a risk of developing respiratory problems. This is due to the exposure of isocyanates present in the car spray paints. This study was conducted to evaluate the effect of isocyanates on pulmonary function parameters of spray painters exposed for a short duration. Methodology: A sample size of 100 male subjects was selected for this case control study. The subjects were 50 males working in the spray industry for $<5 y$ rs and the controls were age matched healthy males not exposed to the spray paints. A standardized respiratory questionnaire was administered to all the workers and spirometry was performed for all the subjects with the help of Medspiror. Results: The pulmonary function parameters $F V C, F E V_{1}, P E F R, F E F 25-75 \%$ and $F E V_{l} / F V C$ ratio of the cases were not significantly changed when compared with that of controls. Conclusion: The absence of reduced pulmonary function parameters in this study may be due to the lesser duration of exposure to the spray painters and usage of protective instrument.
\end{abstract}

Keywords: Car spray painters, pulmonary function test, isocyanates, spirometry, FVC

\section{Introduction}

Pulmonary function tests are powerful tests in detecting the effect of certain chemical exposures on pulmonary function. Automobile factory is a place where workers are exposed to toxic substances, which are harmful to health. In automobile industry, work floor assembly lines chassis move continuously and pass by "Robot Painter" that sprays them and workers assemble the chassis. The paint that is used in sprays contains an isocyanate, a low molecular weight compound which is of a major concern, relating to development of occupational asthma. Car spray painters are exposed to polyurethane products containing diisocyanates [1]. Diisocyanates are cross-linking agents used in polyurethane products like foams, paints, inks, insulating materials, varnishes and rubber modifiers [2]. The most commonly used isocyanate monomers are toluene diisocyanate (TDI), diphenylmethane diisocyanate (MDI), hexamethylene diisocyanate (HDI) and biuret modified HDI [3]. These isocyanate compounds are colorless, yellow or brown liquids with sharp pungent odours. As spray painting creates fine mists that may suspend in air for a short period of time the painters are directly exposed to isocyanate fumes, inducing acute and chronic airflow obstructive diseases. Dermatitis and eczema occurs in dermal contact. The pulmonary effects were characterized by dyspnea, wheezing and bronchial constriction. Eyes, nose and throat irritation with coughing and labored breathing is seen with acute toxicity and in severe exposure it produces hypersensitivity pneumonitis and pulmonary edema. Chronic exposure to isocyanates can lead to immune disorders as well as nasal \& lung lesions like chemical bronchitis, allergic asthma, non specific bronchial hypersensitivity, chronic deterioration in lung function \& hypersensitivity bronchial pneumonitis [4]. Many studies have found acute temporary effects on FVC and FEV in car painters. Despite the extensive use of isocyanates oligomers, in automobile industries, its association on pulmonary function is studied less in India when compared to western countries. Despite the improvements in paint shop materials, practices and control, there are still chances for exposure to isocyanates .In U.S.A, between 50,000 to $1,00,000$ workers are at risk of occupational exposure to isocyanates, and the number is increasing substantially because of the rapidly expanding use of coating materials (Paints), adhesives and binders [5]. Many studies have shown long duration exposure of paint effects on pulmonary function but very few studies are there for short duration exposure of paint effects on pulmonary function hence this study was performed to evaluate the effect of shorter duration exposure of isocyanates on the pulmonary function parameters. 


\section{Materials and Methods}

The study design is of case- control type. This study was conducted in the department of physiology, Meenakshi Medical College Hospital \& Research Institute, Kanchipuram, Tamilnadu, India.

\section{II.1Study Population}

A sample size of 100 subjects was included in this study. The study group were 50 male subjects employed in car spray painting automobile industry between the ages of 19-30 yrs with employment duration of less than 5 yrs. Inclusion criteria were absence of pre-occupational respiratory diseases like asthma, bronchitis, non smokers and a normal physical examination. A standard respiratory questionnaire was administered to all the workers. The questionnaire included respiratory symptoms of the internationally accepted British Medical Research Council respiratory questionnaire and additional questions like smoking, personal protective equipment use, yearly health checkup, educational status \& training in particular work, occupation duration was also elicited. The questionnaire was validated extensively with pilot study and co-researchers. Smokers were excluded from the study. All workers had a general physical examination, specific to respiratory \& smoking habits. Control group were 50 age matched healthy male non-smokers, not exposed to car spray paint.

\section{II.2 Pulmonary function test}

Both the groups performed pulmonary function tests according to ATS/ERS guidelines using Medspiror (Recorders and Medicare Systems). Informed consent was obtained from all the subjects. The Medspiror was self calibrated daily. Pulmonary function tests were carried out in the morning hours. The entire FVC procedure was demonstrated satisfactorily and was instructed to the subjects. The subjects were asked to take maximal inspiration and blow into the mouthpiece as rapidly, forcefully and completely as possible for about atleast 3 seconds. Verbal encouragement was given to the subjects as to continue to exhale the air at the end of manoeuvre to obtain optimal effort. A minimum of 3 acceptable forced vital capacity (FVC) manoeuvres was performed in the standing position with nose pinched and the best manoeuvre was selected and accepted. Each of subjects performed three FVC and the best curve was taken for analysis. The parameters studied were FVC, FEV1, PEFR, FEF25-75\%, FEV1/FVC.

\section{II.3 Statistical analysis}

The results were interpreted as mean and standard deviation and statistical analysis was done using students t-test. $\mathrm{p}$-value of $<0.05$ was considered as significant. Potential confounders were adjusted during the analysis.

\section{Results}

A total of 50 cases and 50 controls were included in this study. The results of the study on pulmonary function in car spray painters are showed in these tables. Table (1) shows the demographic characteristics of control and exposed subjects' i.e age, number of subjects, duration of employment in the current job.

Table 1: Demographic profile of control and exposed subjects

\begin{tabular}{|c|c|c|c|}
\hline Parameters & Controls(50) & Cases(50) & P value \\
\hline Age (yrs) & $28.02 \pm 4.9$ & $26.8 \pm 2.8$ & 0.13 \\
\hline Height (cms) & $165.9 \pm 6.4$ & $166.6 \pm 6.5$ & 0.5 \\
\hline Weight (kg) & $62.7 \pm 9.6$ & $65.5 \pm 10.7$ & 0.15 \\
\hline Duration of employment (yrs) & & $4.45 \pm 2.04$ & \\
\hline
\end{tabular}

\section{Data represented by mean $=\mathrm{SD}$}


Table (2) shows the pulmonary function tests between the controls and the study group

\begin{tabular}{|c|c|c|c|}
\hline $\begin{array}{l}\text { Spirometrx } \\
\text { parameters }\end{array}$ & \multicolumn{1}{l|}{ Control } & Study & \\
\hline FVC $\%$ & $82.3 \pm 13.6$ & $78.6 \pm 12.5$ & 0.1 \\
\hline FEV1\% & $91.48 \pm 13.8$ & $87.2 \pm 13.8$ & 0.1 \\
\hline FEF25-75\% & $87.16 \pm 19.03$ & $88.9 \pm 28.4$ & 0.6 \\
\hline PEFR \% & $92.6 \pm 13.82$ & $87.9 \pm 17.8$ & 0.1 \\
\hline FEV1/FVC & $111.18 \pm 5.3$ & $110.7 \pm 5.9$ & 0.7 \\
\hline
\end{tabular}

The results showed that there was no significant change in pulmonary function tests between both the groups.

\section{Discussion}

The present study was undertaken to evaluate the effect of isocyanates exposure on pulmonary function. In the present study, there was no statistically significant reduction in pulmonary function tests among the spray painters. The reason for this, insignificance could be lesser duration of employment exposure and being nonsmokers and usage of respiratory protective equipment. The results of this study showed no evidence of adverse effects of isocyanates exposure on pulmonary function and also absence of work related respiratory symptoms. Increased risk of airflow obstruction in painters was related to duration of exposure to isocyanate and was independent of the effects of cigarette smoking. It was found that $\mathrm{FEV}_{1}$ and $\mathrm{FVC}$ decrements were significantly associated with the length of exposure to isocyanate[6]. The threshold limit value and permissible exposure limit if are not exceeded, isocyanate induced respiratory effects are little/absent [7]. A relation between peak exposure and reduced pulmonary function in car painters were also observed [8]. In non-smokers positive response to isocyanate exposure was in the form of late or dual response [9]. A reduction in pulmonary function parameters \& asthma like symptoms is highly prevalent in spray-painting industry. Respiratory symptoms and occupational asthma in oliogomer aromatic isocyanates exposed workers are observed in many studies. Specific IgE plays a role in a minority of individuals with respiratory symptoms and IgE mediated mechanism in only a small proportion of the symptomatic individuals [10]. There is a slight average decrease in FVC and FEV1 during a working week which may be of importance in the long run [11]. Car painters who smoke less are less likely to use respiratory protection in highly exposed situations and therefore show a greater decline in lung function. Workers who showed an acute decrease in lung function over a week are vulnerable than other workers and repeated exposure in these workers will result in long term chronic reduction in lung function [12, 13]. An asymptomatic decrease in FEV1 and expiratory flow rates among toluene diisocyanate exposure workers is been observed [14].

\section{Conclusion}

In this present study it was concluded that car spray painters exposed to isocyanates had no pulmonary function abnormality detected through pulmonary function test. There was also no work related respiratory symptoms present in these cases. The reason for the absence of lung function impairment in this study may be less exposure duration time of employment and using of respiratory protective equipment and also all the case subjects were non-smokers.

\section{References}

[1] Chattopadhyay O. Pulmonary Function in Automobile Repair Workers. Ind J of Comm. med 2007;32:1.

[2] Morgan KC, Rager RB. Rise and Fall of the FEV1. Chest, 2000;118(6):1639-1644

[3] Vandenplas O, Malo JL, Saetta M, Mapp CE, Fabbri LM. Occupational asthma and extrinsic alveolitis due to isocyanates:current status and perspectives. Br.J.Ind.Med 1993;50:213-228

[4] Abuelfadl AA, El-Ebiary AA, El-Maddah EI et.al., Pulmonary Toxicity among car spray painters J.Forensic Med. Clin. Toxicol 2010;18:51-63 
[5] Sparer J, Stowe MH, Bello D et.al., Isocynate Exposure in Autobody Ship workers. The Spray study. J Occup Environ Hyg, 2004;1(9):570-81.

[6] Wisnewski, AV, Redlich CA, Mapp CE, Bernstein D I. Polyisocyanates and their prepolymers. In : Asthma in the Workplace and Related Conditions. Bernstein I. L.; Chan- Yeung, M.; Malo, J. L.; Bernstein D. I (Eds.),2006, Taylor \& Francis, New York, P.P. 481-504.

[7] Pronk, A.; Preller, L.; Raulf-Heimsoth M et,al., Respiratory symptoms, sensitization, and exposure response relationships in spray painters exposed to isocyanates". Am. J. Respir. Crit. Care Med.,2007 176:1090-1097.

[8] Dahlqvist M, Tornling G, Plato N, Ulfvarson U. Effects within the week on forced vital capacity are correlated with long term changes in pulmonary function: reanalysis of studies on car painters exposed to isocyanate. Occupational and Environmental Medicine 1995;52:192-195

[9] Vandenplas O, Delwiche JP, Staquet P et.al., Pulmonary effects of short-term exposure to low levels of toluene diisocyanate in asymptomatic subjects. Eur. Respir. J,1999; 13:1144-1150

[10] Glindmeyer HW,Lefante JJ, Rando RJ et.al., Spray painting and chronic airways obstruction. Am. J. Ind. Med 2004;46:104-111.

[11] Eifan AO, Derman O, Kanbur N et.al., Occupational asthma in apprentice adolescent car painters. Pediatr.Allergy Immunol 2005;16:662-668

[12] Taylor, A. J.: Occupational asthma/ Diisocyanates. In: Hunter's Diseases of Occupations. (2000) Baxter, P. J.; Adams, P. H.;Cockcroft, A.; Harrington, J. M. (Eds.), Arnold, London, P.P. 639.

[13] Fletcher CM, Peto R, Tinker C, et al. The natural history of chronic bronchitis. Oxford, UK: Oxford University Press, 1976; 10-34, $70-105$

[14] Whig J, Bansal B, Mahajan R. Work Place Challenge Spirometric Response in Polyurethane (Isocyanate) Paint. Ind J Chest Ds Allied Sci,1994:36,2,73-76 